\title{
Husbandry to industry: Animal Agriculture, Ethics and Public Policy
}

\author{
Jes Harfeld \\ Centre for Bioethics and Nanoethics \\ Aarhus University \\ jeh@teo.au.dk
}

\begin{abstract}
The industrialisation of agriculture has led to considerable alterations at both the technological and economical levels of animal farming. Several animal welfare issues of modern animal agriculture - e.g. stress and stereotypical behaviour - can be traced back to the industrialised intensification of housing and numbers of animals in production. Although these welfare issues dictate ethical criticism, it is the claim of this article that such direct welfare issues are only the forefront of a greater systemic ethical problem inherent to industrialisation. Consequently, this article provides an analysis of the foundational ethical problems in animal agriculture which derive from (I) overly positivistic science and (II) free-market ideology. It will be argued that both these ways of thinking allow for a systematic reification and commodification of animals and that this contributes to language and attitudes which cannot encompass ethical consideration of animals.
\end{abstract}

\section{Introduction}

Industrialisation has dramatically changed the 10,000 year-old agricultural basis of our civilisation. This unprecedented transformation of the last 100-200 years is a well known and well described phenomenon of agriculture in the Western world. From the first combine harvesters in the 1830 s to post-war modern tractors, antibiotics and corporate business models, industrialisation has come to dominate the mindset and practices of agriculture. A part of this industrialisation is the development from traditional animal husbandry to animal industry - a complex historical subject which must, as a field of study draw on interdisciplinary research including historical, political, sociological, technical and cultural studies. The present article is an interdisciplinary philosophical investigation of this development and its ethical ramifications. It is, as such, a combinational analysis of industrial animal agriculture with an eye to the histories of technology and economics. 
The expansion and standardisation of industrialised agriculture is predominantly a post-WW2 occurrence but has its roots deep in the industrialisation movement of the late 19th and early 2oth Centuries. Technological improvement together with economic and social change interacted to bring about an agricultural revolution parallel to - and to a great extent mimicking - the revolution in production industries focusing on non-living products. Farmers throughout the Western world adopted criteria and methods from other types of production industries in order to stay competitive and meet the demands (quantity, reliance, and price) of a continuously growing market. Thus an almost paradigmatic agricultural shift has taken place and its general resemblance to other industries has given rise to the popular reference 'factory farming' - a manner of farming that has had a severe negative side effect on the welfare of the ever increasing animal population in agriculture (Fraser 2001, 181-182). The direct animal welfare problems intrinsic to industrialised agriculture are documented and discussed in a majority of the works of modern animal ethics. Problems concerning confinement, social isolation, overcrowding, lack of natural behaviour, stress during transport and similar issues have been addressed in interdisciplinary studies combining, especially, ethology and philosophy. Of course, scientific advances and the general modernisation of agriculture have also brought about better medical treatment of sick animals, possibilities for better and more adequate feed and technology for better winter housing (Fraser 2001; Sandøe and Christiansen 2008). The presence of grave welfare problems is, however, indisputable and this is of critical importance in animal ethics.

Nonetheless, the interest of the present article is to be found at a different level. Rather than focus on individuals - animals as well as humans - this article deals with some of the contexts in which these individuals exist and function - i.e. the societal systems and ideologies that form the foundation and social structures of modern agriculture. Two of the main societal systems will be discussed: 1) the scientific system as expressed in the adaptation and use of technology and medicine in agriculture, and 2) the economic ideology as 
expressed in the adaptation and use of free market theory in agriculture. With this background the text will take the form of a philosophical criticism of the "de-animalisation" and commodification of animals in modern industrial farming and of the societal systems which promote it. As part of this aim, it will be argued that the scientific and economic systems are incapable of taking ethical values into account. The objectification of farm animals is an example of this. Scientific and economic systems, in their predominant forms, can only approach animals as objects and thus the animals are no longer beings in relation to other beings, but instead become part of machineries which, since they are objects, are devoid of ethical relevance. The primary questions, in this context, thus become: which aspects (or versions) of scientific and economic systems debilitate the ethical consideration of farm animals in our society, and how? From these questions it is the aim of this article to argue that in order to approach and address ethical problems in modern animal agriculture we have to not only direct our attention at the individual levels (animal, farmer, consumer) but also necessarily at the societal and political systems in which agriculture is inherently embedded.

The article is structured in four parts. The first short section, entitled 'Industrialised animals,' is a description and outline of the principal functional aspects of industrialised animal agriculture. Section two, entitled 'Individualism, cost-benefit theory, and valuing animal welfare,' is an analysis of the application of free market economy to animal farming. This entails an investigation into the notion of value and its different definitions and the section will rely in part on contemporary communitarian critiques of cost-benefit theory. Section three, entitled 'Science and technology - square pegs in round holes,' concerns the integration and use of scientific methods and tools in modern animal agriculture. Here I address the manner and extent to which technology has changed what the animal is and its relation to the predominantly human world around it. This section will further consider the mindset or ideology behind traditional technological science and how this could have an effect on 
the understanding of the animal. The fourth section, called 'Things or beings? The problem of ethics in industrialised animal agriculture,' aims to show the connection between market-thinking and scientific ideology - and it is contended that the scientific system and the economic system are not merely linked and intertwined, but are indeed two functions of the same way of objectificational thinking. Lastly, in the conclusion it is argued that this institutionalised way of thinking is detrimental to animal welfare in modern agriculture and that a new inclusive community based approach is needed.

\section{Industrialized Animals}

There is no academic consensus as to the exact definition of industrialised agriculture, but several supplementing, and to a certain degree overlapping characteristics are usually employed. The overall attribute is one of intensification (Fraser 2008, 167-189) which subsequently connects to a number of different areas. In animal agriculture this relates to an intensification of housing systems, i.e. more animals on fewer square metres, increased indoor housing systems and feed efficiency. It, furthermore, relates to intensification in the amount of desired output, i.e. more muscle mass and quicker growth in broilers and pigs, more milk from cows, and more eggs from laying hens. Additionally, industrialisation is identified with an intensification of agricultural management and farming culture. This applies to a focus on monocultural farming where only one species is kept - sometimes just during one phase of the animal's life. It also applies to farm ownership where increasingly larger farms (with more animals) are owned by fewer farmers or, indeed, no farmers at all in the case of agricultural productions run by corporations.

These aspects of intensification rely on a number of scientific innovations that deserve mentioning. Firstly, medical science has had a tremendous effect on both the possibility for and the running of industrialised animal agriculture. The invention and prolific use of antibiotics, vaccines, hormones and other medical technology has been an advantage for the intensification of product output as well as the intensification of housing systems. Medicine increases growth 
rates and enables the close quarter housing of the animals in systems which otherwise make the animal population more susceptible to diseases. Secondly, the technological advances in machinery have, in another parallel to factories, replaced human labour. The animals in industrial agriculture are increasingly both fed and monitored (and cleaned up after) through the use of machines, thus dramatically reducing the number of minutes the caretakers spend on each animal.

\section{Individualism, Cost-Benefit Theory, and Valuing Animal Welfare}

"Everything that has to be controlled has to be measurable. If it cannot be measured, it is an illusion to think that it can be controlled. And if it is measurable it can be priced" (Rasmussen 1993, my translation).

The above quotation from the book "From Social State to Minimal State" by Anders Fogh Rasmussen demonstrates the idea, heavily inspired by the thoughts of John Locke and Robert Nozick, that the best (Nozick would probably say 'most fair') way to run society is through free-market capitalism. In Rasmussen's case this means that government and regulations should concern themselves with measurable (quantifiable) things only. These things can then be priced, i.e. valued in financial cost-benefit terminology. Such freemarket liberalism is, I contend, highly questionable in its endeavour to encompass almost all aspects of our society - including agriculture. The following section will endeavour to demonstrate some of the problems inherent to these theories of laissez-faire liberalism.

Traditional modern animal agriculture is an industry functioning under many of the same parameters as other production industries. Consequently, the influence of cost-benefit theory and the promotion of free-market economy, which shape the conditions for the manufacturing of clothes, diapers, toys, and furniture also shape the conditions for producing animals. This is problematic due to a 
number of critical differences between animal agriculture and other production industries. First and foremost, the products in agriculture - unlike those in other industries - are complex sentient beings with both intrinsic worth (or self-value) and relational ties to other beings (Harfeld 2010). The claim here will be that such beings have value that is not readily accessible through the cost-benefit epistemology of free-market thinking. This is not to say that animals are not priced, marketed, and sold like other goods, rather, the value of animals is not limited to theses aspects.

\section{Sagoff and 'What is it Worth?'}

An analogous assertion has been made by American philosopher Mark Sagoff. His theory, although mainly applied specifically to environmental issues, broadly explores public policy and societal decision-making within areas where ethical values come into play (Sagoff 1984; 2008). Several aspects of it can successfully be employed to highlight problems of value judgement in cost-benefit animal agriculture. Sagoff's idea has developed around the concept of the category mistake of traditional cost-benefit economics in its assessment of values in the environment, in health care, and in other

public domains. Wall Street economics simply cannot take account of the complexity or the nature of aesthetical, societal, and ethical values that, although considered intangible from a financial point of view, are at play when we evaluate and make decisions within the public domain.

First, however, it is important to understand the main assertions of Sagoff's philosophical anthropology. He distinguishes between two different roles according to which the inhabitants of any given society are motivated and act. On the one hand, human beings can have interests and act in ways that are purely individualistic. He calls this the consumer side of us, and being such a person, one would "concern [herself] with personal or self-regarding wants and interests" (Sagoff 1989, 8). As a consumer, you act in accordance with preferences that aim to help yourself or others, closely related. This individualistic position stands in contrast to that of a citizen who is 
concerned not only with his own wants and interests but rather "with the public interest" (Sagoff 1989). Being a citizen is what enables a person to act out of concern for society as a whole. The point of reference and concern is turned away from what I and those close to me want, and instead I care about promoting the benefits of my community independent of my individual wants. This is, for example, the case, whenever someone supports and finances rights or interests of a group of people to whom they do not themselves belong. As citizens they might evaluate this as doing the right thing because it is for the common good and they do this knowing that their actions might have a negative or minimally positive effect on their personal interests. Similarly, Sagoff sees the public protection of nature preserves and wild animals as citizen actions, in which people support things they consider valuable and do so irrespective of any personal usage of said nature and animals. The consumer and the citizen could also be meaningfully understood as two different motivations for actions - the difference between wants and values. Wants are readily accessible through the concepts of market prices and cost-benefit calculations. The level of my wanting of object $X$ gives it a market value that is understandable in the economic language. The price of object $\mathrm{X}$ is dependent upon how much one or more individuals are willing to pay for it, which is again dependent upon how much they want it. According to Sagoff the problem arises when economic analysts attempt to value things within their market theories that are radically different kinds of things. Cost-benefit analysis can, through the wants of consumers, tell us something about the monetary value or cost of, for example, a certain piece of land. It could answer questions as to how much the land would sell for or what it would cost to develop it, etc. This, however, does not say much about the kinds of value that we actually ascribe to many areas in our world - nor indeed to many objects and experiences. Sagoff actually describes the difference between wanting and valuing as the difference between things you value so much that you would pay for them and things you value so much that you would not pay for them. Value in the first sense is called price and value in the second sense is called dignity (Sagoff 2008). To say that something 
has dignity is to say that capturing it in cost-benefit terminology is pointless and...

"... economic analysts who seek to find quasi-market prices for citizen values [...] commit what philosophers call a 'category mistake.' They ask objective convictions and beliefs a question that is appropriate only for subjective wants and desires" (Sagoff 1989, 10).

Love, salvation, cultural legacies, natural wonders, and most of the items on the UNESCO world heritage lists are but a few of the many things whose value, according to Sagoff, would be impossible to understand under the theories of a purely economic mindset. When a person, as a consumer, declares his preference (or want) for the music of Bach as opposed to the music of Mozart, he can only defend this preference by way of personal taste. It is an appetite without foundation in anything but self-regarding desire and the only level of value is how much he would be willing to pay for it. If, on the other hand, he acts as a citizen and declare his preference for the bird-rich marshlands of Northern Europe he will, independently of his personal willingness to pay a certain price for them, be expected to argue for the value of these natural areas from a stand-point which is not his alone. There is no possibility of arguing the reasons behind ' $\mathrm{I}$ like pineapple on my pizza', but, Sagoff says, the discussion about the values of, for example, natural habitats and environmental protection are intrinsically accessible to all members of the community.

\section{Sandel and the Consequences of Selling and Buying}

A similar endeavour to distinguish between what you can price and what you cannot is found in the writings of Harvard Philosopher Michael J. Sandel. In his lectures and in the article What Money Can't Buy: The Moral Limits of Markets (Sandel 2000), he presents a number of cases - e.g. surrogate motherhood and military service to exemplify the problematic expansion of commodification. It is a criticism of what he sees as "the extension of markets and of marketoriented thinking to spheres of life once thought to lie beyond their reach" (Sandel 2000, 93). There are, according to Sandel, two main 
objections against the ever increasing market-making of our lives: coercion and corruption. The argument from coercion is what we could call a background argument and it problematises the market foundation of free agents by questioning how voluntary the actions of these agents really are. If a given society is significantly unequal with little or no distribution of wealth, situations can arise where people are so disadvantaged that they will buy and sell under conditions which could hardly be said to be voluntary in any real sense. If a person, as Sandel describes, sells her organs in order to get money to feed her starving children, it does not warrant labelling as voluntary action. It is a market act due to the coercion of the situation and does not live up to "the ideal of consent" (Sandel 2000, 94). This argument, however, does not target markets and their proliferation but is limited to criticising markets where the background inequality reduces or prevents the truly voluntary actions of the participants. In an entirely fair and equal society the argument from coercion would have very little or nothing to say against an increased general commodification.

The argument from corruption, on the other hand, focuses on the very goods that are commodified and is independent of the equality or inequality of a given society claiming that "certain things should not be bought and sold" (Sandel 2000, 100) irrespective of the level of coercion. The buying and selling of certain goods and practices diminishes and corrupts the character of the goods and practices themselves. One of Sandel's examples is that of surrogate motherhood - an ethical dilemma which has prompted even more discussion since the practice has become global and outsourced to developing countries as portrayed in the documentary Google Baby (Frank 2009). Sandel argues that it is a wrongful (economic) valuation of things like motherhood, fatherhood, and the nurturing of children. These things or goods are indeed of great value although the precise definition of their value is difficult to ascertain. What we do know is that the valuation of motherhood "is different from knowing how much the thing [e.g. motherhood] is worth. It involves a qualitative, not just a quantitative judgment" (Sandel 2000, 101). 
These qualitative judgments are at the heart of Sandel's argument and if one accepts that some goods have qualitative value then it will follow that these goods cannot be converted into a single measure or unit of value.

In section four I will return to Sagoff's and Sandel's central arguments to show how they pertain to animal agriculture: firstly, in that cost-benefit analysis is inappropriate when dealing with things whose value is not only assessable in money and secondly, that there is a certain terminology inherent in cost-benefit thinking which impedes ethical language and action.

\section{Science and Technology - Square Pegs in Round Holes}

Parallel to the emergence and incorporation of free-market economy into agriculture, the farming industry has enthusiastically embraced the developments within science and technology during the last 150 years - from the chilled plough of Jethro Wood to the most recent pharmaceutical innovations. This means that animal production not only functions within the same economic systems as other production industries in society, it even functions via the same tangible methods. The efficiency of assembly line technology together with, especially, medical science has revolutionised the way that we do agriculture as well as the way that it is indeed possible to do agriculture. This, however, has not come about without consequences for both the agricultural profession and the animals. The following section aims to illustrate the background for some of these consequences.

\section{Feyerabend's Defence of Pluralism}

The writings of Paul Feyerabend are notoriously provocative and some of his claims have a problematic tendency towards an illfounded relativism. There are, however, a number of defendable points in his theories, especially their defence of the pluralistic mindset as a plausible counter-view to the natural scientific theories which otherwise tend to dominate society. Feyerabend's work is an 
attempt to problematise - and to a certain, but lesser, extent - to illustrate a remedy for the suggested dogmatism in science. His initial description of and argument against science and the "researchimmanence of scientific standards" (Feyerabend 1980, 9) bear some resemblance to Mary Midgley's criticism of the "imperialistic ideologies" of science (Midgley 2003, 21) as well as to Bernard E. Rollin's reproof of "scientific ideology" (Rollin 2006, 15-16) and the excluding and overly positivistic definition of science and its capacities.

"The common sense of science decrees that a wedge be driven between the truths of science and the truths of ordinary life ...” (Rollin 1998, 6).

"This compartmentalization is inevitable and understandable, but it is not necessarily beneficial ..." (Rollin 1998, 7).

Feyerabend's description of the prevalent scientific community is of a group or system so immersed in its own inner reasons and foundations that it is no longer able to - nor does it seemingly want to - break out of its paradigms, and thus: "Scientists are salesmen of ideas and gadgets, they are not judges of Truth and Falsehood" (Feyerabend 1980, 15). Both Feyerabend and Rollin argue that science is continuously, and for the moment inescapably, caught in its own net of presumptions. In particular, the still prevalent ideas of positivism and materialism have added dimensions to science that are limiting the scope of science and - because modern science is so influential - limiting the scope of society. In other words, the shortcomings of science are visible in the shortcomings of society and its institutions in general.

In many ways the health care sciences are archetypes for such criticism. Because of the underlying (dogmatic) materialistic assumption of human health care as pertaining to "material disturbances which can be localised and identified as to their chemico -physiological nature," (Feyerabend 1980, 16) health care has been locked into a framework that is not unequivocally for the best of 
society or man. Examples of this are numerous in the mental health care sciences, but are also found in more somatic diseases like cancer. In a major report from 2006, the Danish Cancer Society (Kræftens Bekæmpelse), the biggest funding organisation for cancer research in Denmark, carried out a survey of 1,502 cancer patients and their experiences with cancer treatment in the Danish health care system. The report, entitled The World of the Cancer Patient (Grønvold 2006), concludes that cancer patients are not getting the optimal treatment in the current system. It is, however, not the technical skills of the doctors or the medical treatments of which the oncology patients disapprove. The fundamental deficiencies in the treatment of cancer patients are widely perceived, among the patients, as deficiencies of care, compassion, and quality of life. In view of this, the Danish Cancer Society recommended that new criteria be developed, criteria that would more comprehensively describe the core matter of optimal treatment. The problem is, of course, that such new criteria would have to be based on the outcomes of the report and therefore include concepts such as care, compassion, and quality of life, which are difficult, if not impossible, to approach in a system based on medical materialism and ruled by "bodyplumbers" (Feyerabend 1980, 16). Feyerabend presents us with a number of ideas for how to counter the rule of science, and he especially emphasises a societal restructuring that he calls the separation of state and science. Although it is not entirely clear what Feyerabend means by this idea, it does rely heavily on one component: a society with pluralistic structure and opinions.

This point is strongly influenced by the individualistic and liberalistic theories of John Stuart Mill, who, in On Liberty, stresses the notion of pluralism of thought.

"If all mankind minus one were of one opinion, and only one person were of the contrary opinion, mankind would be no more justified in silencing that one person, than he, if he had the power, would be justified in silencing mankind" (Mill 2003, 76). 
With Mill, Feyerabend argues that a "plurality of views is preferable to a uniform intellectual climate" (Feyerabend 1980, 4) because: 1) any opinion or thought, however seemingly insignificant, can still hold truth; 2) even if the opinion is false, some parts of it may still hold valuable truths; 3) a true opinion or thought which goes uncontested by other thoughts will become unreflective prejudice (dogma); 4) this slip into unfounded dogma - or "paradigm blindness" as Rollin calls it (Rollin 2006, 258) - could lead to the loss of meaning and prevent "the growth of any real and heartfelt conviction" (Mill 2003, 116).

Thus equipped with a concept of constructive pluralism, Feyerabend turns his attention to modern science, especially medical science, and its dominant and atomising body-as-a-machine idea. He uses what is normally referred to as "alternative" or "traditional" medical practices to illustrate that many medical traditions have existed and, indeed, continue to exist parallel to, but utterly concealed by, the authoritarian and ill-reflective modern Western medical science. Hopi, Chinese, and traditional African medical traditions should be assessed together with modern medicine and, importantly, this should be an assessment outside the parameters set exclusively by any of the traditions - especially outside the dominant medical science. Although Feyerabend is not entirely clear as to how such an assessment should be conducted, he several times stresses the argument from 'results' (Feyerabend 1980). In our investigation of a seemingly foreign and "strange" medical practice, our assessment of it must, to a large extent, come from the results that it produces both when it is independently evaluated and in comparison to other medical practices. This, however, raises the question of the nature of the results. Most actions, practices, traditions and so on, have some kind of results. Therefore, what we are looking for in Feyerabend's assessment by results-comparison is some positive or 'good' result. What counts as good or a traditional explication of 'the good' is lacking in Feyerabend's work, except that it is not necessarily measurable in the materialistic terms of science. However, in an 
earlier article there is a glimpse of a value theory - an idea of what our results should aspire to.

“... to make people more pleasant and more interesting, to make life happier, to make the world better, to make the beer better, and so on. These are all reasonable" (Feyerabend 1968, 130).

The broad scope and, admittedly, vagueness of this definition are compelling aspects of Feyerabend's theory. Because of the theory's focus on people and their lives as opposed to functions and workings of a body, for example, it leads us back to our example from the Danish cancer patient study. The grievances of the cancer patients were with a system that, due to its intrinsic set of materialistic parameters, could not incorporate treatment and results that are aimed at the intangible choices and the holistic good of the patients. The criticism that Feyerabend directs towards modern science translates to a criticism of any dogmatic, monopolistic institution in our society. It accentuates a justificational problem, pertaining to the development of newer and better theories and traditions, as well as to powerful institutions and their reign over and suppression of other traditions of thought and opinion.

\section{Rollin on Scientific Ideology}

As shown earlier there is a close resemblance in some of the criticisms that Rollin and Feyerabend direct at the scientific system and community. Indeed, Rollin expresses gratitude for Feyerabend's "inspiring and pioneering work towards a realistic philosophy of science" (Rollin 1986, 165) and uses arguments inspired by or corresponding to those of Feyerabend both in the case of animal consciousness (Rollin 1986, 165-171) and related to what he considers natural science's problematic dominance over our society (Rollin 1995b). Rollin, however, focuses his examination on the ideologies that would withhold the relevance of ethics from the spheres of science - and especially from the spheres of animal science. Where Feyerabend's objective is a review of science in general, Rollin maintains an aim at the way science and scientific thinking has 
become a problem in our relationship with animals in research as well as agriculture. This does not amount to a theory which is antiscience, but it should be taken as a "constructive critique of questionable philosophical assumptions which underlie much of current scientific activity" (Rollin 1998, xiii). According to Rollin, these assumptions implicate arguments from logical positivism and logical behaviourism and would thus undoubtedly exclude, among many other things, the mental states of animals due to their alleged unobservability. He argues, however, that such a narrow definition of science would not only be at odds with "normal" common sense but would make the scientific study of things like history and quantum physics impossible since neither of these phenomena is directly accessible or observable either. Rollin defends, in the case of animal mentation, a type of critical anthropomorphism (Rollin 1998) in which the qualities of the animal mind are asserted by a crossreference to species biology, evolutionary continuity, and common sense. He sees the overemphasis on quantification in science as a reductionism which ignores individual qualitative differences. This tendency to look at quantifiable and repeatable functional systems and disregard qualitative personal experiences is what leads some "physicians to see patients as instances of disease rather than as unique individuals" (Rollin 2006, 23) and to engage in objectificational discourses about "the kidney in Room 407" (Rollin 2006, 141). Furthermore, Rollin questions the claim from the scientific community that their work is, or should be, that of valuefree knowledge production.

“... as one scientist said to me, 'We don't make value judgments in science; all we care about is knowledge' " (Rollin 2006, 22).

First of all, he maintains that science itself makes an epistemic value claim when it contends that some types of knowledge gathering, e.g. laboratory based empirical science, are better than other types such as anecdotally based research. Secondly, he criticises what he sees as a prevalent conception among scientists - namely that science is ethics-free, i.e. scientific practice does not concern itself with moral 
matters only amoral facts and any ethical deliberation must, and can only be, done in society outside science. Rollin, of course, does not agree with this notion and maintains that there are no special circumstances which insulate the world of scientific inquiry and discovery from the effects and side effects that come about in its wake. The world of science is not causally or functionally separated from the beings - human and non-human alike - which are positively or negatively affected by its numerous products and methods, whether these are weapons, housing technology, or medicine. One of Rollin's primary examples of this is the emergence and integration of antibiotics and other pharmaceuticals into industrialised animal agriculture.

Whereas a nineteenth-century attempt to raise a hundred thousand chickens in one building would have ended abruptly with the deaths of the animals, technology gave us antibiotics, vaccines, bacterins, and air-handling systems, which allowed the animals to survive and produce, while still experiencing severely truncated welfare (Rollin and Benson 2004, 9).

The scientific discoveries and adaptations enable agriculture to increase profitability and productivity by forcing "square pegs into round holes" (Rollin 2006, 168) and thus circumventing the notion of husbandry and its emphasis on "the ancient contract" (Rollin 2006, 8 ) and mutual benefits. It is important to understand that Rollin not only criticises the concrete activities that potentially diminish animal welfare, but directs his condemnation at the very mindset and (agri) cultural change behind the actions. He sees it as a change from an ancient symbiotic husbandry contract between the farm animal and the farmer in which the animals were given protection from predators, thirst, hunger, and illness in return for their products: clothing, meat, eggs, milk etc. Animal welfare was at the heart of the husbandry contract both from the perspective of practical production - the notion that animals did not produce if they suffered - and its focus on relations between a farmer and his animals, relations that go beyond ownership and economic value. On the other hand, animal science is, as Rollin puts it, "about efficiency and productivity" (Rollin 
and Benson 2004, 8) and its ideological agnosticism inhibits the understanding of the animal as anything but an elaborate machine and thus precludes any relational connection to the farmer.

\section{Things or Beings? The Problem of Ethics in Industrialized Animal Agriculture}

The previous two sections emphasise two different potential concerns in connection with animal agriculture: first, the valuation problems of a free-market ideology, and second, the problem of objectification and quantification in the scientific mindset.

Regarding the first, it is important to understand that neither Sagoff nor Sandel, nor indeed this article, purvey an argument against or a condemnation of markets per se. The buying and selling of goods and services in markets is global, not only in the sense that it goes beyond and across borders, but in that markets exist everywhere. The question is how these markets are constituted. As far as national or international markets go there is no such thing as an entirely free market and the issue is to what degree a given market is free or regulated. The market in itself is a mere mechanism, and as such, an amoral thing. Similarly, some of the established regulations are amoral tuning devices to make the market work "better" (avoiding monopolies and increasing access). There are, however, other regulations that are introduced, not in order to hone the market mechanisms (they might even have an adverse effect on the market) but in order to further something that has a value that transcends the valuational competence of markets. It is the focal point of Sagoff, Sandel, and this article that the idea and application of market thinking and valuation has spread to areas where it is not a competent judge and where its language of value is too poor to capture anything meaningful.

Concerning the second point, that of objectification and quantification in science, I must admit to a certain degree of optimism. When Paul Feyerabend and Bernard Rollin began challenging the established scientific ideas and methods back in the 
70 and 80 , the scientific community was perhaps more clearly dominated by reductionism and materialism than it is today. When Rollin in The Unheeded Cry, as well as in earlier writings describes frequent meetings with scientists and veterinarians "who deny that animals feel pain" (Rollin 1998, 23) and how he was himself, educated in the tradition of positivistic "demand for empirical verification of all meaningful claims" (Rollin 1998, 16) he illustrates a different time in academia. One would be hard pressed, I believe, to unearth scientists today who would actually deny the existence of some kind of experiential inner world or mind of the so-called "higher" animals (pigs, dogs, horses etc.) and that these faculties include the ability to feel pain. This does not, on the other hand, mean that science in general has moved away from positivism as the only path to knowledge. There is still a widespread "epistemological scepticism about animal minds built into the positivistic common sense of science" (Rollin 1998, 24) but the battleground has moved significantly throughout the last 20-30 years. The health and medical sciences increasingly include life-style, social relations and a more holistic view of the patients and the concept of health itself. Similarly, the scientific quarrel in animal science is no longer about the existence of animal consciousness or animal pain, but about the qualitative aspects of that consciousness and about what different kinds of suffering (or positive emotions) animals are capable of. Researchers like Isabelle Veissier and Alain Boissy have ascribed such diverse and complicated emotions as boredom and disgust to sheep (Veissier et al. 2009) whereas these ascriptions would be considered a step too far and problematically anthropomorphic by other scientists (Wynne 2007). The objections of Feyerabend and Rollin are, nonetheless, still appropriate to 1) the areas of science that persist in using quantificational terms in answering questions which are rightly qualitative in nature, and 2) the areas of industry, like modern agriculture, where the scientific ideology has been adopted and endures. 


\section{Agricultural Business and Animal Life as an Object}

I return now to the matter of market economy and its connection to animal welfare in agricultural production. Some practices of modern industrialised agriculture - e.g. crate confinement and lack of behavioural opportunities - are detrimental to the well-being of the farm animals. It is my claim that some of these practices are supported by the free-market system's way of thinking in which agriculture has become so engulfed. This relies, first of all, on the uncontroversial claim that there is a direct correlation between how we perceive and understand phenomena in the world and the attitudes and behaviour we exhibit toward these phenomena. Roughly speaking, this is what happens when I see an apple and decide to eat it. My perception of the apple and understanding of its properties leads me to a certain attitude towards apples, i.e. that they are things that I can eat and digest. I can, of course, be wrong about this in many ways. In the case of an apple it could happen that the object was a wax model and unfit for consumption - that would be a mistake of identity. Or I could, in the case of another fruit or vegetable, simply be wrong about its qualities - that is I could be wrong about ascribing edibleness to poisonous yew berries. Similarly, different ethical systems often have, as one of their foundations, a theory to locate the parameters of ethical relevance by the characteristics of beings. If, in the case of hedonistic ethics, a certain being is understood as something which does not have the capability for feeling pain and/or pleasure then this radically changes the types of behaviour toward this 'something' opposed to the behaviour towards a being which is understood to have such capabilities. When Sandel asserts that the buying and selling of goods and services corrupts said goods and services, he is guilty of a subtle but important inaccuracy. That which is corrupted is not necessarily the goods and services themselves but our perceptions, and thus, attitudes and behaviours towards them. When we approach something as being within the framework of cost-benefit economy, we are viewing it through epistemological lenses that shape our understanding of it. In modern animal agriculture, the free market establishes a certain 
value to a specific animal - or, in the case of meat production, a value to a kilo of the specific animal. This value is strictly monetary and reflects the amount of money that has been used in the production of the animal (or a kilo of the animal) and the amount of money for which this could be sold to retailers and consumers. This, however, is a form of valuation better fitted to things like washing machines and clothing whose value is not only external to the objects themselves, but relies on their use and on the attitudes and behaviours of individual consumers.

On the contrary, animals have value that is intrinsic to themselves, i.e. they are ends-in-themselves (Regan 1985) and have active lives and needs that matter (are of value) to them (Rollin 1992, 104; Dennett 1996, 4). Thus, a valuation which strives to understand and appraise animals merely in the use-value terminology of the free market is doomed to capture only instrumental and external aspects - and consequently fails to take into account any other answers to the question: what is the animal's value? This is what Sagoff identifies as the category mistake (Sagoff 1989, 10); it is a mistake about what kinds of value we are talking and asking about - or as Sagoff's prime inspiration Immanuel Kant differentiates it:

Im Reiche der Zwecke hat alles entweder einen Preis, oder eine Würde. Was einen Preis hat, an dessen Stelle kann auch etwas anderes als Äquivalent gesetzt werden; was dagegen über allen Preis erhaben ist, mithin kein Äquivalent verstattet, das hat eine Würde (Kant 2004, 49).

In the kingdom of ends everything has either a price or a dignity. What has a price can be replaced by something else as its equivalent; what on the other hand is above all price and therefore admits of no equivalent has a dignity (author's translation).

This appropriately illustrates Sagoff's point as to the evident dissimilarity between different types of value and it is the claim of both Sagoff and Sandel that, with respect to some instances of goods and services, one type is correct and the other erroneous. This is a 
convincing claim as long as we remind ourselves that the focus should be on the over-prevalent and wrongful use of cost-benefit evaluation and not on asserting the intrinsic falseness of this kind of evaluation altogether. Whether an evaluation of something is correct cannot merely be intrinsic to that something, but must refer back to the kind of question we are asking - whether its context is ethical, economic, or aesthetic.

Thus, our first question must always be directed at the meaning of the question: 'what is it worth?' This presents us with a very pluralistic way of evaluating the world and the things and beings in it. It is obvious that things, beings, goods, and services have a certain monetary value in a society where these are bought and sold. The fact that the selling of babies might be ethically wrong does not necessarily connote that the monetary valuation of babies is a faulty method within its own concept - its own question. There might be very sound economic methods about how to economically appraise babies. The problem is that the pluralistic evaluation of the world has succumbed to a few, very powerful methodologies and ideologies. Cost-benefit economics and free-market thinking are examples of such ideologies which have, together with similar approaches (e.g. narrow science as we will see later on), become bastions of power in society. They have influenced the way we think about our world to such a degree that they occasionally appear to be accepted as the only real ways through which we can talk about the value of things around us.

Returning to the question of the farm animal, we must recognise that there is a plurality of ways to evaluate these beings and their lives. Each of these ways is coherent and accurate in its own right with respect to the context in which the question of value is asked. It is apparent that pigs in agricultural production are sold and bought, and through this price-valued. It is, however, not apparent that this is the only or the correct way in which to evaluate these beings. The evaluative questions and answers of free-market economics do not provide us with the full knowledge spectrum of the animal's value. 
Indeed, the dominance of the economic perspective in agriculture serves to blur the plurality of evaluations and diminish any applicable ethical evaluation. This effectively undermines the ethical standing of the animals and, by association, the welfare of the animals. This undercutting of ethical standing is a by-product of cost-benefit terminology and the way this terminology presents the world and its content to us. When, as free-market theory would have it, goods and services are exchangeable for an equivalent sum of money, it entails a problematic uniformity on two levels. Firstly, it defines whatever is thus exchanged as being the same as (or treatable as) other things, since they are dealt with in the same manner (i.e. sold and bought). Secondly, it defines whatever is exchanged as being convertible to money. Both levels indicate a strong objectificational view of the world - a view that can only understand entities in the world as objects or things whose value is external to the entities themselves. In our present line of inquiry this is what has come to be known as the commodification of animals (Donovan 2006) and it is comparable to the 'Verdinglichung' (literally 'thing-making') of Marxist theory or the process which modern Marxist Ted Benton describes as reification.

"In this central dimension of our relation to non-human animals [as consumers to commodities], they are subjected to an intensified reification, a systematic exclusion from recognition as beings with subjective life, or sentience, let alone interests or rights" (Benton 1993, 92).

This 'exclusion from recognition' necessarily entails that they cannot be considered as beings within the sphere of ethical consideration. Whatever a theoretical tradition holds as ethically relevant subjects - Singer's sentient beings, Regan's "subject-of-alife" (Regan 2004, 243) or Dennett's beings whose being matters to themselves (Dennett 1996, 4) - it almost certainly excludes mere things. Inanimate objects such as chairs, pencils, houses etc. are of a category of things in the world without direct ethical relevance. If cost -benefit economy is a dominant mindset of modern agriculture then a dominant mindset of modern agriculture lacks the ability to recognise 
anything as more than an object, and is thus predetermined to classify animals as objects and outside the realm of ethics. This classification is not simply another way of talking about animals independent from and parallel with ethical evaluation. It is in reality the negation of ethical evaluation in the sense that it establishes an amoral terminology. The problem is not that the market terminology is immoral - it is actually entirely oblivious to the concept of morality.

\section{Agriculture Science and Animal Life as a Machine}

Another dominant mindset in society is derived from a certain form of natural science and it is in many ways analogous to the way that narrow, free-market economy approaches the world around us. The Rollin metaphor describes the problem as making square pegs fit in round holes. He argues that certain scientific and technological actions are too focused on functions and become detrimental to animal welfare because they increase the productivity of the animals to such a degree that suffering is inevitable. However, science and technology are not only problematic because they, under certain circumstances, create welfare problems for the animals. Parallel to my criticism of a cost-benefit evaluation approach to animals in agriculture, I would contend that scientific terminology in a specific, narrow-empirical version has been adopted by industrialised agriculture in such a way that it seriously inhibits us from talking about animal welfare in general and animal ethics specifically. The problem has its roots in Descartes' infamous concept of animals as automata with reactions to stimuli but without corresponding emotional states (Descartes 1912). In the dualistic philosophy of Descartes this was the opposite of humans whose true essence lay in the possession of an immaterial soul. The idea of automata-animals continued seamlessly together with Lockean empiricism in the positivistic natural sciences of the 20th century. Logical positivism had its predominant philosophical influence in the first three decades of the 2oth century through the work of the Vienna Circle and its associates. Although, proponents of a positivistic stance in the 
philosophy of science started rejecting the theory again as early as the late 1930s, the movement as such and Alfred Ayers book Language, Truth and Logic (Ayer 1952, originally 1936) in particular, had tremendous impact on an already very positivistic natural scientific community. As Paul B. Thompson describes it:

The book may have served as a manifesto and a warrant for two generations of budding scientists to return to their empirical studies confident in the belief that not only could they safely ignore the ministrations of theologians and ethicists, but also that it was their duty as rigorous scientists to do so (Scanes and Miranowski 2004, 339).

This has led to a "prohibition of 'metaphysical' language" (Schmid and Thompson 1999, 9) within the natural sciences which is still detectable in contemporary terminology and methodology. I do, however, agree with Thompson that the willingness to include and undertake ethical justifications in the agricultural sciences is entering a more favourable phase after having been comparatively derailed throughout the later part of the 2oth century (Thompson 2002). Societal norms together with changing public focus have supported a growing scientific inquiry in animal science - and especially ethology - with emphasis on topics like stress and welfare. These are notions that obviously fundamentally elude any kind of logical positivistic scientific approach. Thus, the accusation of unduly positivistic approaches to animal science is only directed at the areas of science which still persist in their rejection (or semi-rejection) of metaphysical and ethical language. I would characterise this sort of constricted verification-heavy scientific inquiry as a narrow science and it is, unfortunately, overwhelmingly the methodology and ideology that has prevailed in practiced animal agriculture. Thus, issues and problems in agricultural management are addressed in terms of narrow science and by applying corresponding technological solutions.

A serviceable example of such an approach is the welfaremeasurement system of the Danish Cattle Federation (DCF). This system relies on a scheme developed by the DCF in order to make on- 
farm welfare assessments for cattle, but in fact it only addresses a number of different features which are only at best related to animal welfare. The DCF assessment scheme focuses on "only the presence or absence of illness, injuries and dirt” (Ingemann et al. 2009, 492) and fails in this narrow scope to take into account the multitude of different welfare relevant frustrations and positive emotions brought on by other factors. There are, both in academia and in society in general, many diverging and competing understandings of animal welfare - but any concept within an agriculture influenced by narrow science tends to exclude subjectivity and reify the animals into the machinery of production. In this sense, the use of antibiotics and tail docking is not related to the welfare or indeed the health of the subjective animal, but is merely directed towards the proper function and health of the animal as part of the material system. Exactly because such a physicalistic world view lacks the metaphysical language and facility to include concepts of intrinsic worth, it becomes only a practical concern about function and output, whether square holes are constructed for square pegs or square pegs altered to fit in round holes. Like the cost-benefit economic mindset, narrow science and its applied agricultural technology are trapped in quantificational (and positivistic) ways of thinking that exclude them from evaluations that lie outside the operational functionality of the system. In this way, the scientists and farmers who claim that science and technology have nothing to do with ethics are correct. Natural science, in the narrow sense I defined, is correct in assuming that its methodology is incapable of approaching ethical aspects or values that lie outside the restricted quantificational understanding of science. Its inherent methodology of inquiry and limited language simply excludes it from finding any ethical wrongs (or rights) in the world. This, however, does not mean that we should abandon narrow science. It merely illustrates that narrow science has limitations that prevent it from entering into ethical discourse and (partially) into the welfare debate. 


\section{Conclusion - Animals and Society}

As two sides of the same coin, the examples of narrow science and narrow cost-benefit economy demonstrate how reification and amoralisation are inescapably part of their structure. An illustration of this reification by language is the designation 'unit' which equals 1,000 pounds of live animal weight. This labels cattle at approximately one unit - whereas you would need nine animals to have one unit of hog for slaughter and 455 animals to have one unit of broiler chicken. When we characterise and talk about animals as atomised units in a production system we impede any society driven consideration focused on their subjective lives and we install attitudes in handlers and ordinary citizens which are detrimental to the animals' welfare.

If we want to change this and take farm animal ethics seriously, we must move beyond ethics of individuals and incorporate ethics of communities, in other words: political philosophy. In order really to assess animal welfare and to evaluate animal agriculture ethically the questions asked cannot only be directed at individuals and their actions and attitudes. It must also always be a matter of political philosophy - i.e. addressing the situations and problems at the level of communities, social structures, and politics. The focus of farm animal ethics must continuously be a matter of the responsibilities and actions of the persons - farmers, retailers, consumers - as they make their choices in food production, sale, and purchase. However, it is important to realise that these individual 'ethical actors' are embedded in contexts and systems that in themselves can be considered relevant ethical actors. It is along similar lines that Danish philosopher Klemens Kappel argues for a combination of individual and collective initiatives when we are faced with challenges whose ethical structures are such that individual strategies alone would not be effective (Det Etiske Råd 2010, 75-90). Animal agriculture is a massive, worldwide, and omnipresent industry with strong connections to national and international economies, politics, and 
science. Thus, it is exactly an ethical structure which calls for collective strategies and political solutions.

Politically, the ethical dilemmas of animal agriculture could be addressed in a number of ways but this article is focused on two influences that I take to be especially problematic: 1) a political philosophy which takes animal ethics seriously must reject a society solely or excessively based on free-market economy and support voluntary and involuntary regulations and economic constrictions which promote an animal inclusive 'triple bottom line' for companies and farms. 2) A political philosophy which takes animal ethics seriously must also consider how to reduce the impact of narrow science and technology in animal agriculture. This may prove to be somewhat more complicated - albeit not necessarily more difficult than the political economic change. One tactic could be to increase the support for research projects which include the metaphysical language of welfare such as the EU project Welfare Quality® (www.welfarequality.net) or institutions like official and universitybased animal ethics councils or institutional animal care and use committees. The main focus, however, must be one of educational politics. The emphasis on directing university education and research towards the needs and wants of private businesses must be abandoned, together with the positivism that fuels it. Overcoming the narrow science ideology is a matter of changing a scientific culture a culture which has its roots firmly in the educational system of universities. An animal conscious political philosophy must target this and argue for politically supported information and education of farmers and, especially, scientists and students.

"We can rest only when examination of ethical issues that are presuppositional to and generated by science are as much second nature to scientists as are the double helix or the Krebs cycle ...” (Rollin 2007, 48).

Primarily, however, animal agriculture must become a community concern and as such be dealt with through public and informed reflection in our society. If we concur that farm animals in 
our societies are ethically relevant beings, then this brings them onto the political stage and inserts them into our common social order into our ethical community. This does not mean, as some anti-animal rights advocates propose, that cows should be given the right to vote. It does, however, mean that we, if we are acting as Sagoffian citizens, must concern ourselves with the plight and lives of farm animals. As individuals we can do this by investigating the vast and complex workings of the agriculture and food industries and act upon our knowledge when purchasing groceries. Yet, this individual strategy is very limited in its scope when the ethical structure of the dilemmas is on a systematic level in society.

One of the effects of modern industrialised animal agriculture was the immense decrease in people working within the business. In a few generations, technology, management techniques, and economic conditions have vastly diminished the number of people with either direct or indirect relations to agriculture and food processing. This communal estrangement from a fundamental part of our society means that knowledge about agriculture and farm animal welfare is reserved to experts, investigative reporters, and very inquisitive and persistent individuals. The answer to this must be a strategy that is communal and based upon an adequate quantity and quality of information gathered and guaranteed by the state as an active arm of the community. Furthermore, the state must provide a continuous public debate where access is not determined by the political, social, or economic power wielded by the participants.

Lastly, even with a political philosophy working for animal ethics, are we not faced with the predicament of all animal agriculture being, by definition, an objectification and commodification of animals? Even the most ethically attentive animal farmer keeps her animals in order to turn them into things: pork chops, steaks, fried drumsticks - and she probably barters with her neighbours exchanging half a dozen eggs for a couple of pounds of ground beef. These things are, of course, objectification and commodification at an entirely different scale than industrialised agriculture, but it is 
objectification and commodification nonetheless. This is, however, nothing extraordinary in our ethical deliberation. All people treat each other as objects or means to an end from time to time, but this only constitutes an ethical problem when these types of behaviours are constant or prevalent and exclude the treatment of relevant others as ends in themselves. As long as animal agriculture exists in our societies, ethically conscientious citizens must engage and debate this dichotomy between the commodification and intrinsic value of farm animals.

\section{Acknowledgements}

I am, as always, indebted to my two main advisors from Aarhus University: Birte L. Nielsen from the Faculty of Agricultural Sciences and Ulrik B. Nissen from the Centre for Bioethics and Nanoethics. Furthermore, I would like to thank Mickey Gjerris from Centre for Bioethics and Risk Assessment at Copenhagen University for his comments and constructive criticism.

\section{References}

Ayer, Alfred J. 1952. Language, truth, and logic. Dover Pubns.

Benton, Ted. 1993. Natural relations: Ecology, animal rights and social justice. London: Verso.

Dennett, Daniel C. 1996. Kinds of minds. New York: Basic Books.

Descartes, René. 1912. A discourse on method. Reprinted ed. London: Dent.

Det Etiske Råd. 2010. Vores mad og det globale klima - etik til en varmere klode. Copenhagen: Det Etiske Råd.

Donovan, Josephine. 2006. Feminism and the treatment of animals: From care to dialogue. Signs: J ournal of Women in Culture and Society 31 (2).

Feyerabend, Paul K. 1980. Democracy, elitism, and scientific method. Inquiry 23 (1): 3-18.

---. 1968. Science, freedom, and the good life. The Philosophical Forum 127-135. 
Frank, Zippi B. 2009. Google Baby.

Fraser, David. 2008. Animal welfare and the intensification of animal production. The Ethics of Intensification: 167-89.

---. 2001. Farm animal production: Changing agriculture in a changing culture. J ournal of Applied Animal Welfare Science 4(3): 175-190.

Grønvold M. 2006. Kræftpatientens verden. Copenhagen: Kræftens Bekæmpelse, (Salogruppen).

Harfeld, Jes. 2010. Philosophical ethology - on the extents of what it is to be a pig. Society \& Animals (forthcoming).

Ingemann, Rikke, Peter Sandøe, P. Enemark, and B. Forkman. 2009. Conflicting goals of welfare assessment schemes: A case study. Animal Welfare 18 (4): 487-95.

Kant, Immanuel. 2004. Grundlegung zur Metaphysik der Sitten. Vandenhoeck \& Ruprecht.

Midgley, Mary. 2003. The myths we live by. Routledge.

Mill, John Stuart, and Gertrude Himmelfarb. 2003. On liberty. New ed. London: Penguin.

Rasmussen, Anders F. 1993. Fra socialstat til minimalstat: En liberal strategi. Copenhagen: Samleren.

Regan, Tom. 2004. The case for animal rights. Berkeley: University of California Press.

- - . 1985. The case for animal rights. Paperback ed. ed. Berkeley, Calif.: Univ. of California Press.

Rollin, Bernard E. 2007. Overcoming ideology: Why it is necessary to create a culture in which the ethical review of protocols can flourish. ILAR J ournal. 48 (1): 47-53.

-- . 2006. Science and ethics. Cambridge University Press.

- - . 1998. The unheeded cry: Animal consciousness, animal pain, and science. Expanded ed. ed. Ames: Iowa State University Press.

---. 1995a. Farm animal welfare: Social, bioethical, and research issues. Ames, Iowa: Iowa State University Press.

--_. 1995b. The Frankenstein syndrome. Cambridge University Press. 
---. 1992. Animal rights and human morality. New York: Prometheus Books.

-- - 1986. Ideology, ethics, and history: A reply to Feyerabend, Rachlin, and Leahey. New Ideas in Psychology 4 (2): 165-71.

Rollin, Bernard E., and John Benson. 2004. The well-being of farm animals: Challenges and solutions. Ames, Iowa: Blackwell Publishing.

Sagoff, Mark. 2008. The economy of the earth: Philosophy, law, and the environment. Cambridge: Cambridge University Press.

---. 1989. The economy of the earth: Philosophy, law, and the environment. Cambridge: Cambridge University Press.

---. 1984. Animal liberation and environmental ethics: Bad marriage, quick divorce. Osgoode Hall Law J ournal 22: 297.

Sandel, Michael J. 2000. What money can't buy: The moral limits of markets. Tanner Lectures on Human Values 21: 87-122.

Sandøe, Peter, and Stine B. Christiansen. 2008. Ethics of animal use. Copenhagen, Denmark: University of Copenhagen.

Scanes, C. G., and J. A. Miranowski. 2004. Perspectives in world food and agriculture, 2004. Wiley-Blackwell.

Schmid, A. A., and Paul B. Thompson. 1999. Against mechanism: Methodology for an evolutionary economics. Working Paper \#99-39, Michigan State University, Dept. of Agricultural Economics.

Thompson, Paul B. 2002. The legacy of positivism and the role of ethics in animal science. British Society of Animal Science: http://www.bsas.org.uk/downloads/annlproc/Pdf2001/263.pdf (accessed June 28th 2010).

Veissier, I., A. Boissy, L. Desire, and L. Greiveldinger. 2009. Animals' emotions: Studies in sheep using appraisal theories. Animal Welfare 18 (4): 347-54.

Wynne, C. D. L. 2007. What are animals? Why anthropomorphism is still not a scientific approach to behavior. Comparative Cognition \& Behavior Reviews 2: 125-135. 